\title{
Imbalance of Th17/Treg in Different Subtypes of Autoimmune Thyroid Diseases
}

\author{
Cui Lia,b Jianghong Yuan ${ }^{b, c}$ Yuan-feng Zhu ${ }^{b}$ Xiang-ju Yang ${ }^{b}$ Qiong Wang ${ }^{b}$ \\ Jian $\mathrm{Xu}^{\mathrm{d}}$ Shuang-tao He $\mathrm{H}^{\mathrm{d}}$ Jin-an Zhang ${ }^{\mathrm{d}}$ \\ ${ }^{a}$ Department of Geriatrics, Xijing Hospital of Fourth Military Medical University, ${ }^{b}$ Department of \\ Endocrinology, The First Affiliated Hospital of Xi'an Jiaotong University, 'Department of Nephrology, \\ Xi'an Central Hospital, Xi'an; 'Department of Endocrinology, Jinshan Hospital of Fudan University, \\ Shanghai, China
}

\section{Key Words}

Graves' disease (GD) • Hashimoto's thyroiditis (HT) • Graves' ophthalmopathy (GO) • T helper 17 cell (Th17) • Regulatory T cell (Treg)

\begin{abstract}
Aims: To clarify the imbalance of Th17/Treg in different subtypes of autoimmune thyroid diseases (AITDs) including Graves' disease(GD), Hashimoto's thyroiditis(HT) and Graves' ophthalmopathy (GO). Methods: 47 patients with AITD (including 16 GD, 15 HT, and 16 GO) and 12 healthy controls were enrolled in this study. The percentages of Th17 and Treg cells, the ratio of Th17/Treg, as well as their related transcription factors RORyt and Foxp3 mRNA in peripheral blood mononuclear cells (PBMCs) were measured by flow cytometry and real-time quantitative PCR Results: Compared with those in control group, the percentage of $\mathrm{CD} 4^{+} \mathrm{IL}-17^{+} \mathrm{T}$ cell(Th17) and the mRNA expression of its transcription factor RORyt were higher in PBMCs of AITDs $(P<0.05)$, particularly in HT subgroup $(P<0.01)$. The percentage of $\mathrm{CD}^{+}{ }^{+}$Foxp $3^{+} \mathrm{T}$ (Treg) cells and its transcription factor Foxp3 mRNA were significantly decreased in PBMCs of GD $(P<0.05)$. In addition, the ratio of Th17/Treg was elevated in AITD group and GO subgroup $(P<0.01)$. In $G O$ subgroup, the patients with clinical activity score $(C A S)$ above 4.5 had higher percentages of Th17 than those with CAS ranging from 3 to $4.5(P<0.05)$. Conclusion: Increased Th17 lymphocytes may play a more important role in the pathogenesis of HT and GO while decreased Treg may be greatly involved in GD.

\section{Introduction}

Autoimmune thyroid diseases (AITDs), a group of organ-specific autoimmune diseases, mainly include Graves' disease (GD), Hashimoto's thyroiditis (HT), and Graves' ophthalmopathy (GO). GO is the most frequent extrathyroidal manifestation of GD and also the most common cause of adult exophthalmos. It occurs in about $50 \%$ of patients with GD, 
and $3-5 \%$ is sight-threatening [1]. It is suggested that the environmental factors trigger the occurrence of AITDs under genetical background. However, the specific mechanism of AITDs yet remains unknown, particularly, the causes the different subtypes of AITDs with a variety of manifestations. Furthermore, we and other investigators have found that distinct AITDs phenotypes may even share common susceptibility genes $[2,3]$. In our another study, we found that the miRNA-target gene network might be involved in the pathogenesis of GD [4].

Advances in cellular immunoglogy have opened a new era of or new insights into exploring the mechanisms of immune related diseases. It is well known that Th1/Th2 cell equilibrium is necessary to maintain the normal balance of the immune system. The disruption of Th1/Th2 balance is attributed to the development of many autoimmune diseases. In HT, Th1-type cell and its cytokines-mediated cellular immune response are overwhelming [5-7].While in GD, Th2-type cytokines-mediated humoral immune response is predominant $[7,8]$. Th17 cell, a recently identified T helper lymphocyte of CD4 positive, acts by secreting its main cytokine IL-17A. It has been well documented that Th17 cell is implicated in the development of different infections, various inflammations and carcinomas [9-11]. Regulatory T cell (Treg), another type of lymphocytes, negatively regulates immune responses and confine them to a proper extent [12]. Like Th1/Th2, Th17/Treg is also a pair of balance in the immune system. It has been shown that Th17/Treg homeostasis was broken in multiple autoimmune diseases $[13,14]$. We and other investigators once conducted research on Th17 or Treg lymphocytes in GD or HT [15-17]. However, there has been neither study on Th17/Treg in G0 nor a comparative analysis of Th17/Treg in different types of AITDs. In the present study, we investigated Th17/Treg cells in three types of AITDs simultaneously and comparatively.

\section{Material and Methods}

Subjects: Forty-seven newly diagnosed AITDs patients (16 with GD, 16 with GO and 15 with HT) were recruited. They had never received any anti-thyroid drugs or immune regulators. Neither did they have other commitant autoimmune diseases or allergic diseases. The diagnoses of HT and GD were made on the basis of clinical manifestations and laboratory results as well as the criteria in our previous paper [15]. The ocular complication of GD, i.e. GO, was diagnosed according to symptoms and signs as well as orbital imaging (CT and MRI). Twelve healthy volunteers were selected as controls. The demographics and clinical characteristics of the subjects are shown in Table 1. The clinical activity score (CAS) of each GO patient was determined according to the standard of American Thyroid Association [18] as shown in Table 2. The research project was approved by the Ethics Committee of the First Affiliated Hospital of Xi'an Jiaotong University.

\section{Methods}

Blood Samples. Peripheral venous blood samples were collected from the patients and healthy volunteers. All subjects fasted for $12 \mathrm{~h}$. The collection tubes contained $0.2 \mathrm{~mL}$ of sodium heparin. The peripheral blood mononuclear cells (PBMCs) were prepared using Ficoll-Hypaque density centrifugation and then stored at $-80^{\circ} \mathrm{C}$ with Trizol for extracting total mRNA. Other PBMCs were separated into two tubes for flow cytometric analysis.

Flow cytometric analysis of Treg and Th17. PBMCs were separated into $2-6 \times 10^{6} / \mathrm{ml}$ in each tube. For Treg assay, PBMCs were incubated with anti-human CD4-FITC (BD Bioscience, USA) at $4^{\circ} \mathrm{C}$ for 30 min in darkness. After fixation and permeabilization, cells were stained with anti-human Foxp3-PE (BD Bioscience, USA) for $30 \mathrm{~min}$ at $4^{\circ} \mathrm{C}$ in darkness. As for Th17 assay, cells were stimulated with phorbol myristate acetate (PMA $50 \mathrm{ng} / \mathrm{mL}$ ) and ionomycin $(1 \mu \mathrm{g} / \mathrm{mL})$ (America Enzo life) with the presence of monensin $(0.7 \mu \mathrm{l} /$ $\mathrm{mL}$ ) (BD Bioscience, USA) at $37^{\circ} \mathrm{C}$ and $5 \% \mathrm{CO} 2$ for $4 \mathrm{~h}$. Then they were stained with anti-human CD4-FITC. Fixation and permeabilization were performed with fix/perm buffer. Cell pellet was resuspended in $100 \mu \mathrm{l}$ BD Perm/Wash ${ }^{\mathrm{TM}}$ buffer (BD Bioscience, USA). For the staining of Th17 cells internal antigen, anti-human IL$17-\mathrm{PE}$ was added at the bottom of the tube, vortexed and incubated for $30 \mathrm{~min}$ at $4^{\circ} \mathrm{C}$ in the dark. Cells were washed with perm/wash buffer $(1 \times)(2 \mathrm{ml})$, and then were centrifuged $5 \mathrm{~min}$ at $500 \mathrm{~g}$ at room temperature. 
Table. 1. Demographics and clinical characteristics of patients and controls. Data are shown as mean \pm SD. Con: control; M: male; F: female; FT3: free T3; FT4: free T4; TgAb: thyroglobulin antibody; TPOAb: thyroperoxidase antibody

\begin{tabular}{lcccc}
\hline Groups & GD & GO & HT & Con \\
\hline Number (M/F) & $16(4 / 12)$ & $16(3 / 13)$ & $15(3 / 12)$ & $12(3 / 9)$ \\
Age $(\mathrm{yr})$ & $39.25 \pm 11.84$ & $39.60 \pm 6.57$ & $38.00 \pm 10.98$ & $36.88 \pm 6.29$ \\
T3 $(\mu \mathrm{g} / \mathrm{dL})$ & $10.66 \pm 18.73$ & $2.11 \pm 1.25$ & $1.67 \pm 0.93$ & $11.17 \pm 1.4$ \\
$\mathrm{~T} 4(\mu \mathrm{g} / \mathrm{dL})$ & $29.41 \pm 30.45$ & $21.19 \pm 49.89$ & $14.47 \pm 22.30$ & $6.58 \pm 1.58$ \\
FT3 $(\mathrm{ng} / \mathrm{mL})$ & $32.06 \pm 16.74$ & $11.31 \pm 9.36$ & $7.87 \pm 6.71$ & $5.53 \pm 1.92$ \\
FT4 $(\mathrm{ng} / \mathrm{mL})$ & $91.39 \pm 54.19$ & $27.18 \pm 23.93$ & $14.6 \pm 3.94$ & $6.90 \pm 2.60$ \\
TSH $(\mu \mathrm{U} / \mathrm{mL})$ & $0.08 \pm 0.06$ & $1.48 \pm 2.08$ & $4.69 \pm 2.94$ & $2.78 \pm 0.42$ \\
TgAb $(\%)$ & $28.41 \pm 19.38$ & $25.39 \pm 18.99$ & $215.29 \pm 656.27$ & $<30 \%$ \\
TPOAb $(\mathrm{U} / \mathrm{mL})$ & $1607.20 \pm 1494.32$ & $1379.9 \pm 1412.99$ & $2070.51 \pm 1345.23$ & $<15$ \\
\hline
\end{tabular}

Table. 2. Clinical features and CAS of patients with GO. Patient number: $16 . \mathrm{M}=$ male, $\mathrm{F}=$ female; CAS: Clinical activity Score. The activity score range from 3 to 9, which indicated active Graves' ophthalmopathy

\begin{tabular}{|c|c|c|c|c|c|c|c|c|c|c|c|c|c|c|c|c|}
\hline Patient number & 1 & 2 & 3 & 4 & 5 & 6 & 7 & 8 & 9 & 10 & 11 & 12 & 13 & 14 & 15 & 16 \\
\hline Sex & $\mathrm{F}$ & M & $\mathrm{F}$ & $\mathrm{F}$ & $\mathrm{F}$ & $\mathrm{F}$ & $\mathrm{F}$ & $\mathrm{F}$ & $\mathrm{F}$ & M & $\mathrm{F}$ & $\mathrm{F}$ & M & $\mathrm{F}$ & $\mathrm{F}$ & $\mathrm{F}$ \\
\hline Age & 30 & 35 & 48 & 38 & 44 & 25 & 40 & 46 & 49 & 35 & 36 & 41 & 39 & 44 & 38 & 46 \\
\hline Pain & + & & + & + & + & + & + & + & & + & + & + & + & + & & + \\
\hline Redness of eyelids & + & + & + & + & + & + & & + & + & + & + & & + & + & & + \\
\hline Redness of conjunctiva & + & + & + & + & + & + & + & + & + & + & + & + & + & + & + & + \\
\hline Chemosis & + & + & + & + & & & + & + & + & + & + & + & + & & + & + \\
\hline Swollen caruncula & & & + & & & + & & & & + & & & + & & & \\
\hline Eyelid edema & & & + & & & + & & & & + & & & + & & & + \\
\hline Increased proptosis & & & & & + & + & & & & + & + & + & + & & & \\
\hline $\begin{array}{l}\text { Decrease in visual } \\
\text { acuity }\end{array}$ & & & & & + & + & & & & + & + & + & & & + & + \\
\hline Decrease in motility & & & & & & & & & & + & + & + & & & & \\
\hline $\begin{array}{l}\text { Clinical activity score } \\
\text { (CAS) }\end{array}$ & 4 & 3 & 6 & 4 & 5 & 7 & 3 & 4 & 3 & 9 & 7 & 6 & 7 & 3 & 3 & 6 \\
\hline
\end{tabular}

In the end, the internal staining of IL-17 was analyzed immediately by flow cytometry using a BD FACS Calibur (BD Pharmingen), or suspended with $2 \%$ formaldehyde solution of PBS until they were analyzed during 24 hours.

\section{Real time quantitative PCR}

Total mRNA from stored PBMCs was extracted with the Trizol reagent (TianGen Biotech) according the manufacturer's instructions. Then the mRNA was reversely transcribed to cDNA with reverse transcription reagent kits (TianGen Biotech). The reverse transcription system consists of random 6 mers and primerscript RT enzyme mix 1 (Primescript RT reagent kit, TakaRa, China). The PCR amplification of cDNA was performed using SYBR Premix EX Taq II (Primescript RT reagent kit). The sequences of primers were as follows: for ROR $\gamma t$, sense, 5'-CTG CCC ATC ATT GCT GTT AAT CC-3'; antisense, 5'-GCT GTG ATC TTG CCC AGA ACC-3': for Foxp3, sense, 5'-CTA CGC CAC GCT CAT CCG CTG G-3'; antisense, 5'-GTA GGG TTG GAA CAC CTG CTG GG-3': for $\beta$-actin, sense, 5'-ATC GTG CGT GAC ATT AAG GAG AAG-3'; antisense, 5'-AGG 


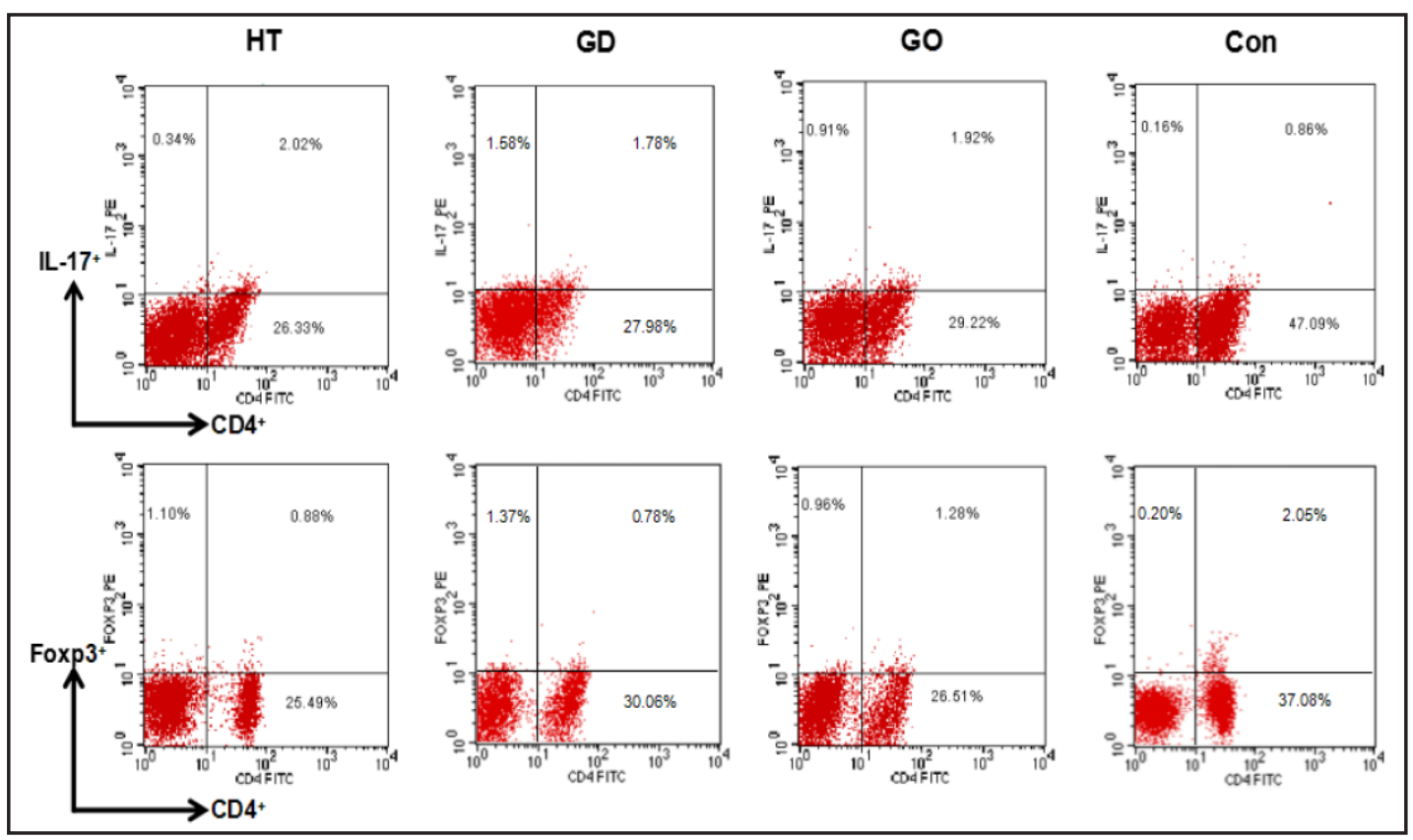

Fig. 1. The expression of CD $4^{+} \mathrm{IL}-17^{+}$lymphocytes and $\mathrm{CD} 4^{+} \mathrm{Foxp} 3^{+}$Tregs in PBMCs from patients with GD, HT, GO and healthy controls by flow cytometry.

AAG AAG GCT GGA AGA GTG-3'. Gene specificity was confirmed by a single peak in melting curve analysis. Amplification cycles ( 40 cycles) were as follows: 3 min at $95^{\circ} \mathrm{C}, 5 \mathrm{sec}$ at $95^{\circ} \mathrm{C}, 30 \mathrm{sec}$ at $61^{\circ} \mathrm{C}, 45 \mathrm{sec}$ at $72^{\circ} \mathrm{C}$.

\section{Statistical analysis}

All continuous data are expressed as mean \pm SD. Data were analyzed using parametric and nonparametric tests. Mean group values were compared by ANOVA. Paired t test and Wilcoxon rank-sum test were used for related two samples. The data were processed using chi-square test. For the data of RT-PCR, we used the $2^{-\triangle \triangle C T}$ method. $\mathrm{P}<0.05$ was considered as statistically significant. SPSS 13.0 was used for statistical analysis.

\section{Results}

In our study, we measured the percentages of Th17 and Treg cells by flow cytometry (Fig. 1). It showed that the percentage of $\mathrm{CD} 4^{+} \mathrm{IL}-17^{+} \mathrm{T}$ cells was significantly higher in patients with HT $(\mathrm{P}=0.003)$, GD and GO $\left({ }^{*} \mathrm{P}<0.05\right)$ than in normal controls (Fig. $\left.2 \mathrm{~A}\right)$. On the other hand, the percentage of $\mathrm{CD}^{+}{ }^{+} \mathrm{Foxp} 3^{+}$Treg cells was lower in the patients with AITDs, especially GD ( $\mathrm{P}=0.047)$, although there was no significant difference between HT and GD (Fig. 2B). Also the ratio of Th17/Treg was higher $\left({ }^{*} \mathrm{P}<0.01\right)$ in the patients with AITDs than in controls (Fig. 2C). In contrast, in patients with GO, the percentage of Th17 was significantly increased $(\mathrm{P}=0.035)$ in the ones with CAS above 4.5 when compared with those with CAS between 3 and 4.5 (Fig. 2D). Regrettably, we did not find the correlation between the Th17/ Treg ratio and GO activity.

When we detected the expression of different transcription factors ROR $\gamma \mathrm{t}$ and Foxp3 mRNA by real-time PCR, we found the levels of ROR $\gamma \mathrm{t}$ mRNA were significantly augmented in patients with AITDs compared with those in normal controls. These results were much in agreement with the above cellular analyses. Additionally, ROR $\gamma \mathrm{t}$ mRNA levels were even much higher in HT than in GD and GO $\left({ }^{*} \mathrm{P}<0.05\right)$ patients (Fig. $\left.3 \mathrm{~A}\right)$.

In comparison with that in healthy controls, the transcriptional level of Foxp3 was obviously decreased in GD and GO $\left({ }^{*} \mathrm{P}<0.05\right)$ patients (Fig. 3B). Although the expression of Foxp3 mRNA was also reduced in HT patients, the difference was not significant. 


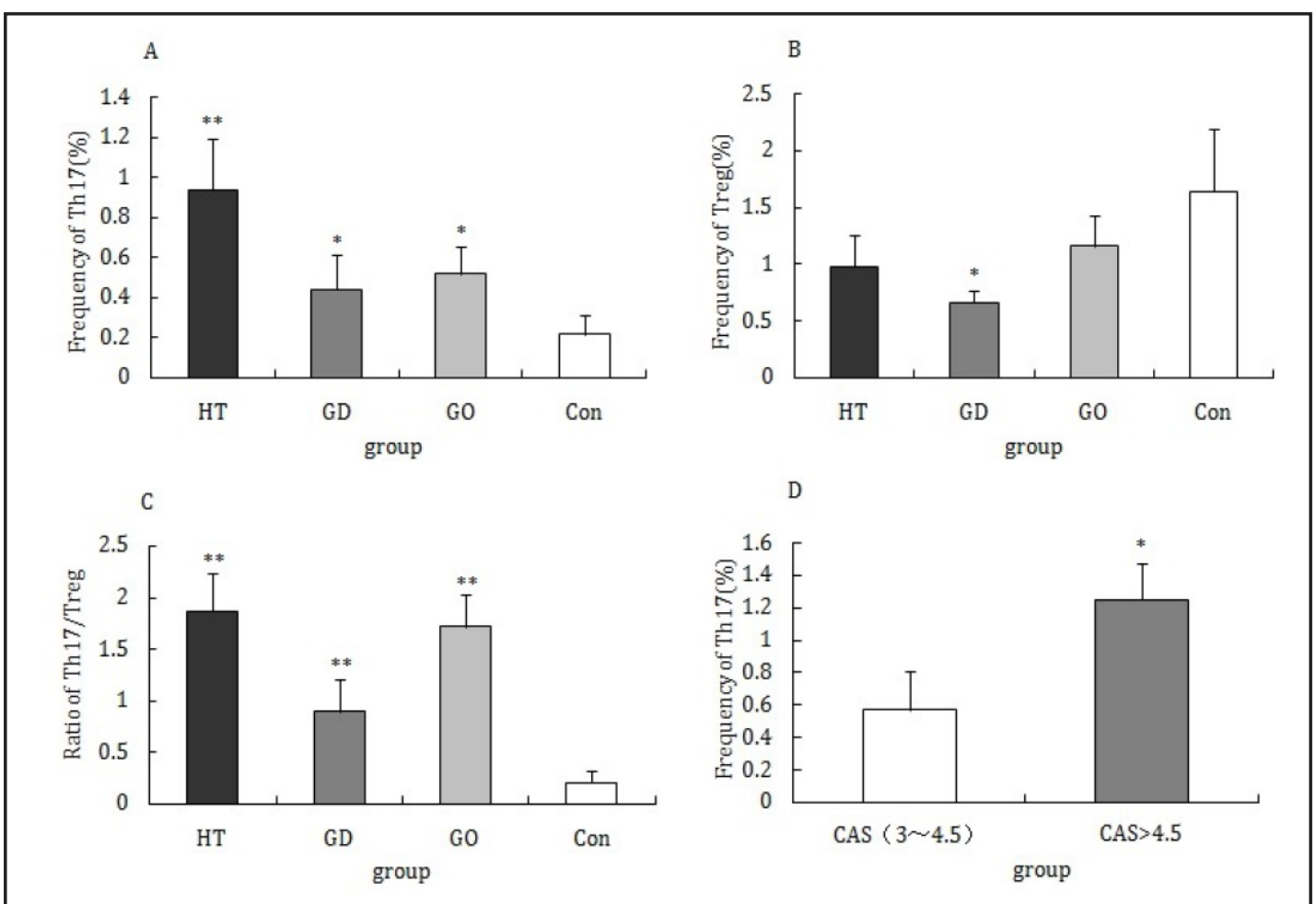

Fig. 2. The frequency of CD4+IL-17+T cells and CD4+Foxp3+Tregs in AITD patients and controls. The percentages of Th17 lymphocytes and Tregs were detected by flow cytometry. Black bars correspond to HT, dark gray bars to GD, gray bars to GO, White bars to Con (A, B, C). *, $\mathrm{P}<0.05$; **, $\mathrm{P}<0.01$. Con, control.

A

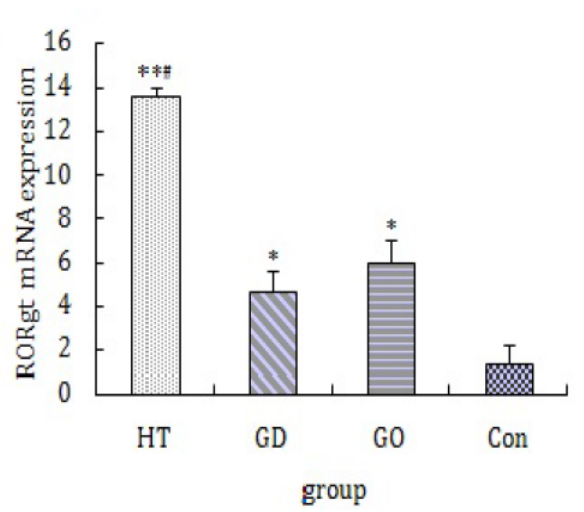

B

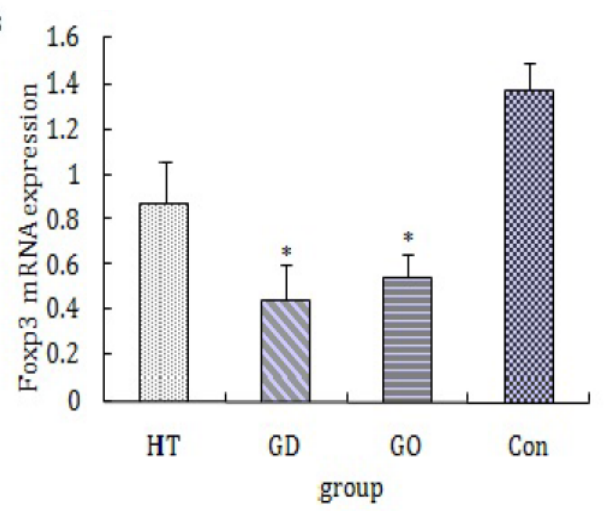

Fig. 3. The expression of RORyt and Foxp3 mRNAs in AITDs patients and normal controls. A. The expression of orphan retinoic acid nuclear recepter(ROR $\gamma \mathrm{t})$ is increased in AITDs than in controls $(*, \mathrm{P}<0.05$; **, $\mathrm{P}$ $<0.01$ ). Contrast to GD and GO, the expression of ROR $\gamma$ t is much higher in HT ( $\#, P<0.05$ ). B. The expression of mRNA levers of forkhead box P3(Foxp3) is decreased in GD and GO than in healthy control(*, $\mathrm{P}<0.05)$.

\section{Discussion}

Th17 lymphocyte is a newly discovered $\mathrm{T}$ helper cell characterized by the production of IL-17A. Treg, a kind of immune regulating lymphocyte, plays a negative role by secreting cytokines like IL-10 and TGF- $\beta$. It has been reported that Th17/Treg imbalance is involved in the development of multiple immune related diseases.

In our study, we found an apparently reduced percentage of CD4+Foxp3 $3^{+}$Treg in GD patients (Fig. 2B), together with a decreased expression of its transcription factor Foxp3(Fig. 
3B). Similar to our results, the frequency of $\mathrm{CD} 4^{+} \mathrm{CD} 25^{+} \mathrm{Foxp} 3^{+} \mathrm{T}$ cells and the expression of Foxp3 mRNA were found decreased significantly in the peripheral blood cells of Ad-TSH289 immunized mice, an animal model of GD. But there was no difference in Th17 cells from those in Ad-control mice (19). It probably indicates that Tregs, but not Th17 cells, plays a predominant role in the pathogenesis of GD. Our findings are also consistent with Klatka's. They found lower percentages and absolute counts of Treg cells in GD teenagers as compared with healthy adolescents [17]. A little different from us, in Nanba's study, they found the percentage of peripheral Th17 cells was higher in patients with intractable GD, whose antithyrotropin receptor antibody (TRAb) remained positive despite treatment with anti-thyroid drugs for more than 5 years [20].

Other researchers have observed an increase in the number of Th17 cells in the spleen and thyroid tissue of iodine-induced autoimmune thyroiditis in nonobese diabeticH2h4 mice, a mouse model of HT. However, the severity of intrathyroidal lymphocyte infiltration, also the titers of antithyroglobulin autoantibodies, was obviously reduced in iodine-treated IL-17-/- mice when compared with wild-type mice, so they believed that Th17 exerts an important role in the pathogenesis of autoimmune thyroiditis [21]. Nicte and his collegues explored Th17 lymphocytes and its cytokines (IL-17, IL-22, IL-6 and IL23 ) in the peripheral blood of AITD patients and the results showed the number of Th17 lymphocyte and the synthesis of its cytokines were enhanced, especially in HT [22]. Also another study showed that intrathyroid infiltrating Th17 cells and serum IL-17 levels were significantly increased in HT patients [16]. In our work, Th17 lymphocyte (Fig. 2A) and its transcription factor ROR $\gamma$ t mRNA (Fig. 3A) increased in patients with AITDs and ROR $\gamma \mathrm{t}$ mRNA increased significantly in patients with HT compared with those with GD. Therefore, we speculated that Th17 has a critical role in the pathogenesis of HT.

For a long time, people have been interested in the mechanism of GO. Not only the number of $\mathrm{CD}^{+} \mathrm{T}$ and the ratio of $\mathrm{CD}^{+} / \mathrm{CD}^{+} \mathrm{T}$ are considerably increased in $\mathrm{GO}$ patients, but also the percentage of Th1 lymphocytes and the ratio of Th1/Th2 cells are significant higher in patients with GO, indicating that Th1-type $\mathrm{CD} 4^{+}$cell might play a dominant role in the pathogenesis of GO [23]. Other researchers analyzed Thelper (Th) cell subsets in orbital adipose/connective tissues of GO patients, and Th1-type clone was detected predominantly in patients with recent onset $(<2 \mathrm{yr})$. In contrast, Th2-type clone was overwhelming in patients with more remote onset ( $>2 \mathrm{yr}$ ) of the disease [24]. Our team found an increased number of CD $4^{+} I L-17^{+} \mathrm{T}$ cells and a higher expression of ROR $\gamma \mathrm{t}$ mRNA in GO patients, but not in GD patients. Furthermore, the peripheral Th17 cells significantly enhanced in patients with severe GO (CAS>4.5) than those with mild disease (CAS between 3 and 4.5)(Fig. 2D). Interestingly, unlike GD, the difference in Tregs and its transcription factor (Foxp3) was found not to be significant between GO patients and healthy controls. Therefore, we speculated that Th17 had a critical influence on the development of GO, while Tregs mainly participated in the pathogenesis of GD.

To conclude, our research demonstrated the breaking of Th17/Treg balance in AITDs. We here initially reported that the immune response shift to Th17 was more pronounced in GO than in HT and GD. In addition, this immune bias was associated with the disease activity of GO. Our study may have practical applications. For example, it has already documented that IL-17A neutralization may alleviate the early stage of silica-induced lung inflammation and delay its progression [25]. Quite recently, a bispecific anti-TNF $\alpha / \mathrm{IL}-17$ antibody showed superior efficacy in blocking inflammatory cytokine and chemokine responses in the culture of human fibroblast-like synoviocytes from rheumatoid arthritis, and that this antibody displayed a protective impact on the bone of arthritic mice [26]. Therapeutic approaches for AITDs depending on correcting the imbalance of Th17/Treg are expected.

\section{Funding}

This work was supported by grants from the National Natural Science Foundation of China (81070627, 81270871). 


\section{Cellular Physiology Cell Physiol Biochem 2016;40:245-252

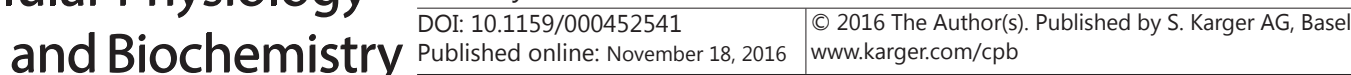

Li et al.: Imbalance of Th17/Treg in AITD

\section{Acknowledgements}

The authors thank all of the participants in the present study including members of the Medical Laboratory Center of Xi'an Jiaotong University.

\section{Disclosure Statement}

The authors declare no financial or commercial conflict of interest.

\section{References}

1 Bartalena L, Pinchera A, Marcocci C: Management of Graves' ophthalmopathy:reality and perspectives. Endocr Rev 2000;21:168-199.

-2 Song RH, Yu ZY, Wang Q, Muhali FS, Jiang WJ, Xiao L, Shi XH, He ST, Xu J, Zhang JA: Polymorphisms of the TNFAIP3 region and Graves' disease. Autoimmunity 2014;47:459-465.

-3 Muhali FS, Cai TT, Zhu JL, Qin Q Xu J, He ST, Shi XH, Jiang WJ, Xiao L, Li DF, Zhang JA: Polymorphisms of CLEC16A region and autoimmune thyroid diseases. G3(Bethesda) 2014;4:973-977.

-4 Qin Q Wang X, Yan N, Song RH, Cai TT, Zhang W, Guan LJ, Muhali FS, Zhang JA: Aberrant expression of miRNA and mRNAs in lesioned tissues of Graves' disease. Cell Physiol Biochem 2015;35:1934-1942.

5 Kocjan T, Wraber B, Repnik U, Hojker S: Changes in Th1/Th2 cytokine balance in Graves' disease. Pflugers Arch 2000;440:R94-95.

6 Kallmann BA, Hüther M, Tubes M, Feldkamp J, Bertrams J, Gries FA, Lampeter EF, Kolb H: Systemic bias of cytokine production toward cell-mediated immune regulation in IDDM and toward humoral immunity in Graves' disease. Diabetes 1997;46:237-243.

7 Heuer M, Aust G, Ode-Hakim S, Scherbaum WA: Different cytokine mRNA profiles in Graves' disease, Hashimoto's thyroiditis, and nonautoimmune thyroid disorders determined by quantitative reverse transcriptase polymerase chain reaction (RT-PCR). Thyroid 1996;6:97-106.

8 Miyauchi S, Matsuura B, Onji M: Increased levels of serum interleukin-18 in Graves' disease. Thyroid 2000;10:815-819.

-9 Bettelli E, Korn T, Kuchroo VK: Th17: the third member of the effector T cell trilogy. Curr Opin Immunol 2007;19:652-657.

10 Martinez GJ, Nurieva RI, Yang XO, Dong C: Regulation and function of proinflammatory TH17 cells. Ann N Y Acad Sci 2008;1143:188-211.

11 Miossec P: IL-17 and Th17 cells in human inflammatory diseases. Microbes Infect 2009;11:625-630.

12 Bacchetta R, Passerini L, Gambineri E, Dai M, Allan SE, Perroni L, Dagna-Bricarelli F, Sartirana C, MatthesMartin S, Lawitschka A, Azzari C, Ziegler SF, Levings MK, Roncarolo MG: Defective regulatory and effector T cell functions in patients with FOXP3 mutations. J Clin Invest 2006;116:1713-1722.

13 Zeng C, Shi X, Zhang B, Liu H, Zhang L, Ding W, Zhao Y: The imbalance of Th17/Th1/Tregs in patients with type 2 diabetes: relationship with metabolic factors and complications. J Mol Med (Berl) 2012;90:175-186.

14 Kleczynska W, Jakiela B, Plutecka H, Milewski M, Sanak M, Musial J: Imbalance between Th17 and regulatory T-cells in systemic lupus erythematosus. Folia Histochem Cytobiol 2011;49:646-653.

15 Qin Q Liu P, Liu L, Wang R, Yan N, Yang J, Wang X, Pandey M, Zhang JA: The increased but non-predominant expression of Th17- and Th1-specific cytokines in Hashimoto's thyroiditis but not in Graves' disease. Braz J Med Biol Res 2012;45:1202-1208.

16 Li D, Cai W, Gu R, Zhang Y, Zhang H, Tang K, Xu P, Katirai F, Shi W, Wang L, Huang T, Huang B: Th17 cell plays a role in the pathogenesis of Hashimoto's thyroiditis in patients. Clin Immunol 2013;149:411-420.

17 Klatka M, Grywalska E, Partyka M, Charytanowicz M, Kiszczak-Bochynska E, Rolinski J: Th17 and Treg cells in adolescents with Graves' disease. Impact of treatment with methimazole on these cell subsets. Autoimmunity 2014;47:201-211.

18 Bartalena L, Tanda ML: Clinical practice. Graves' ophthalmopathy. N Engl J Med 2009;360:994-1001.

19 Zhou J, Bi M, Fan C, Song X, Yang R, Zhao S, Li L, Li Y, Teng W, Shan Z: Regulatory T cells but not T helper 17 cells are modulated in an animal model of Graves' hyperthyroidism. Clin Exp Med 2012;12:39-46. 


\section{Cellular Physiology Cell Physiol Biochem 2016;40:245-252 \begin{tabular}{l|l|l} 
DOI: 10.1159/000452541 & $\begin{array}{l}\text { O 2016 The Author(s). Published by S. Karger AG, Basel } \\
\text { www.karger.com/cpb }\end{array}$ \\
\hline
\end{tabular} \\ Li et al.: Imbalance of Th17/Treg in AITD}

20 Nanba T, Watanabe M, Inoue N, Iwatani Y: Increases of the Th1/Th2 cell ratio in severe Hashimoto's disease and in the proportion of Th17 cells in intractable Graves' disease. Thyroid 2009;19:495-501.

-21 Horie I, Abiru N, Nagayama Y, Kuriya G, Saitoh O, Ichikawa T, Iwakura Y, Eguchi K: T helper type 17 immune response plays an indispensable role for development of iodine-induced autoimmune thyroiditis in nonobese diabetic-H2h4 mice. Endocrinology 2009;150:5135-5142.

-22 Figueroa-Vega N, Alfonso-Pérez M, Benedicto I, Sánchez-Madrid F, González-Amaro R, Marazuela M: Increased circulating pro-inflammatory cytokines and Th17 lymphocytes in Hashimoto's thyroiditis. J Clin Endocrinol Metab 2010;95:953-962.

23 Xia N, Zhou S, Liang Y, Xiao C, Shen H, Pan H, Deng H, Wang N, Li QQ: CD4+ T cells and the Th1/Th2 imbalance are implicated in the pathogenesis of Graves' ophthalmopathy. Int J Mol Med 2006;17:911-916.

24 Aniszewski JP, Valyasevi RW, Bahn RS: Relationship between disease duration and predominant orbital T cell subset in Graves' ophthalmopathy: J Clin Endocrinol Metab 2000;85:776-780.

25 Chen Y, Li C, Weng D, Song L, Tang W, Dai W, Yu Y, Liu F, Zhao M, Lu C, Chen J: Neutralization of interleukin17A delays progression of silica-induced lung inflammation and fibrosis in C57BL/6 mice. Toxicol Appl Pharmacol 2014;275:62-72.

-26 Fischer JA, Hueber AJ, Wilson S, Galm M, Baum W, Kitson C, Auer J, Lorenz SH, Moelleken J, Bader M, Tissot AC, Tan SL, Seeber S, Schett G: Combined inhibition of tumor necrosis factor $\alpha$ and interleukin-17 as a therapeutic opportunity in rheumatoid arthritis: development and characterization of a novel bispecific antibody. Arthritis Rheumatol 2015;67:51-62. 